This document is published in:

European Economic Review (2002), 46(1), 93-115.

DOI: 10.1016/S0014-2921(01)00085-X

C 2002 Elsevier Science B.V 


\title{
Modelling price competition across many markets (An application to the Spanish loans market)
}

\author{
Jordi Jaumandreu ${ }^{\mathrm{a}, *}$, Joaquín Lorences ${ }^{\mathrm{b}}$ \\ ${ }^{\mathrm{a}}$ Universidad Carlos III de Madrid, C/Madrid 126, 28903 Getafe (Madrid), Spain \\ ${ }^{\mathrm{b}}$ Universidad de Oviedo, Oviedo, Spain
}

\begin{abstract}
The purpose of this work is the structural modelling of price competition in a productdifferentiated industry in whic h many firms of varying size c ompete ac ross many independent small markets, with the target of identifying price behaviour. We apply it to model competition among the more than 79 banks that were active in the Spanish loans market during the period 1983-1991, using micropanel data. A model in which national banks (as opposed to regional and local banks) fully internalize their cross-rate effects in pric ing is selec ted as the model that best fits the data. Our framework allows us to estimate the dead-weight loss due to market power, and to decompose it assessing the part attributable to price c oordination.
\end{abstract}

JEL classification: L13; G21

Keywords: Price behaviour; Independent markets; Market power; Price coalitions

\section{Introduction}

Since the early 1980s the European banking industry has been the object of many regulatory changes with the goal being to enhance competition. Market

* Corresponding author. Tel.: + 34-916245737; fax: + 34-916249329

E-mail address: jordij@eco.uc3m.es (J. Jaumandreu). 
power in the bank loans market during this period has been found to be substantial, although decreasing over time in some activities as the result of the impact of deregulation (see Neven and Röller, 1999). Spain was one of the countries to apply such policies intensively. During the 1980s, Spanish authorities liberalized interest rates and commissions, promoted entry to the industry (mainly of foreign banks), and removed barriers to encourage competition from savings banks. Loan pricing behaviour, however, had still not shown any apparent changes in Spain by the end of our sample period (1991), even though changes in conduct began to appear in the compensation of deposits 2 years before.

The reason has been informally attributed to the difficulty of breaking up coordination between banks in a highly concentrated market despite the great number of competing entities (more than 79). In fact, the six largest private banks (reduced to four through two mergers by the end of the period) accounted for more than half of the branches and loans, and led corporate groups that 20 additional banks belonged to. Although at the other end of the distribution there were an important number of small regional, local and foreign banks, which together with the savings banks were intended to put pressure on competition, it is a fact that they compromised with persistently high interest rates. This makes the Spanish market of the period an interesting asymmetrical context in which to investigate price behaviour and, in particular, to try to uncover the specific form of bank pricing coordination.

To investigate price behaviour, we apply an industry model in which many banks that supply a slightly differentiated product (loans) compete across many independent geographic submarkets. ${ }^{1}$ Product differentiation raises symmetric rate effects at the local level (i.e. the banks in a given local market compete with each other), but bank activities are unequally distributed across markets, which determines unequal sizes. This model is both suitable and serves a purpose. On the one hand, it closely mirrors the structure of banking. Banks can be seen in their two main activities (deposits, loans) competing across many small independent local submarkets (quarters of cities, towns ...), where each branch faces the rivalry of the other branches in the market, but differing in the local markets they cover. On the other, it offers a precise guide for how to specify the unequal patterns expected for the own and cross-price effects in the context of many asymmetrical firms, and hence, how to constrain them for estimation purposes.

Our empirical exercise consists of the estimation of the (constrained) own and cross rate effects for 79 banks (with data on the loans granted and the rates charged by these banks from 1983 to 1991) and the testing of competing

\footnotetext{
${ }^{1}$ See Sutton (1998) on the notion of independent submarkets, and De Juan (1999) on its applicability to the geographic structure of Spanish retail banking.
} 
hypotheses of behaviour, using the estimated effects to specify alternative pricing equations. The estimates of the model are then used to perform an analysis of welfare loss due to the exercise of market power and, in particular, the part due to price coordination. It is, therefore, an exercise in the tradition of the empirical studies of industries with market power (see Bresnahan's (1989) survey). ${ }^{2,3}$

The structural modelling of the oligopolistic interaction in banking has recently been a subject of interest. Even starting from a different theoretical framework, our study shares many of the characteristics of Barros (1999) work: the market is taken as differentiated and consisting of submarkets; market structure is exploited to obtain the theoretically based relationships; and several equilibria are tested. But Neven and Röller (1999) also provide an example of structural modelling at a country-aggregate level that clearly justifies the relevance of more detailed works for the European banking industry.

Estimates of our model are sensible, the results of the test point to the superiority of partially collusive models in explaining the data (suggesting a price coalition of the national banks), and the welfare dead-weight loss is estimated in some years to be a quarter of a percentage point of the national GDP. This validates the common belief about collusive behaviour affecting the loan rates of the main Spanish banks at the time.

The rest of the paper is organized as follows. Section 2 presents our assumptions on the optimizing behaviour of banks. Section 3 specifies demands and discusses their estimation, as well as the equilibria to be considered and the way to test them against each other. Section 4 summarizes the relevant facts in the Spanish loans market during the period. Section 5 explains the empirical model, Section 6 presents the econometric results, and Section 7 performs the welfare analysis. Finally, Section 8 summarizes the conclusions.

\section{The optimizing behaviour of banks}

We model banks along the lines of the so-called Monti-Klein model of a bank with market power (see Freixas and Rochet, 1997), in a version with product differentiation and some dynamics. Banks can borrow or lend in the interbank

\footnotetext{
${ }^{2}$ We deal with the problem of the number of parameters to be estimated in a product differentiated industry (Bresnahan, 1989; Berry, 1994) by applying direct constraints on the structure of price effects (similar to, for example, Slade, 1986, 1992). A different approach is the discrete-choice specification of demands (see Berry et al., 1995).

${ }^{3}$ In testing a given number of well-defined equilibrium hypotheses, as opposed to testing a single behaviour or checking the value of some unspecified behavioural parameter, we adopt the practice pioneered by Gasmi et al. (1992) and followed, among others, by Pazó and Jaumandreu (1999).
} 
market at a given interest rate, which constitutes the (common) marginal cost of funds. The profit of a bank is therefore the sum of the intermediation margins on loans and deposits minus management costs. If management costs are additive, the decisions regarding the lending and borrowing rates of the banks are separable. In this and the following sections, for the sake of simplicity, we take management costs to be zero. In the empirical application, we will reintroduce it in the simplest form of a constant unit management cost.

For the period that we study, most of the loans were formalized under fixed interest rates. Therefore, we assume that the target of the banks is to maximize the discounted intertemporal flow of expected profits that will be derived from the credit open (or renewed) at a given moment of time. For example, the problem solved by a Bertrand player in order to optimally set the interest rates at each moment $t$ is (dropping the player's subindex for simplicity)

$$
\underset{r_{t}, r_{t+1}, \ldots}{\operatorname{Max}} V=\sum_{t}^{\infty} \sum_{s=0}^{S} \delta^{s} \mathrm{E}\left[\pi_{t+s}\left(r_{t}, r_{\mathrm{R} t}\right)\right]
$$

where $\pi_{t+s}$ is the profit that will be derived at moment $t+s$ from the credit open at time $t$ under the interest rate $r_{t}$ and when the vector of rates of the rivals is $r_{\mathrm{R} t}$, $\delta$ is the discount factor, and $S$ represents the maximum length of time at which some credit open at $t$ will remain.

Now, write the demand for new credit at moment $t$ as $l\left(r_{t}, r_{\mathrm{R} t}\right)$ and assume that the fraction of this credit that will remain after $s$ periods of time will be $\lambda_{s}$ (with $\lambda_{0}=1$ and $\left.\lambda_{S+1}=0\right)$. Then, calling $i$ the interbank rate, expected profits for $t+s$ will be $\mathrm{E}\left(\pi_{t+s}\right)=\left(r_{t}-i_{t+s}^{\mathrm{e}}\right) \lambda_{s} l\left(r_{t}, r_{\mathrm{R} t}\right)$. With this specification, the relevant FOC to set $r_{t}$ is

$$
\begin{aligned}
\frac{\partial V}{\partial r_{t}}= & l\left(r_{t}, r_{\mathrm{R} t}\right)+\left(r_{t}-i_{t}^{\mathrm{e}}\right) \frac{\partial l}{\partial r_{t}}+\delta \lambda_{1}\left[l\left(r_{t}, r_{\mathrm{R} t}\right)+\left(r_{t}-i_{t+1}^{\mathrm{e}}\right) \frac{\partial l}{\partial r_{t}}\right]+\cdots \\
& +\delta^{S} \lambda_{S}\left[l\left(r_{t}, r_{\mathrm{R} t}\right)+\left(r_{t}-i_{t+S}^{\mathrm{e}}\right) \frac{\partial l}{\partial r_{t}}\right]=0
\end{aligned}
$$

that gives the price equation

$$
r_{t}=i^{\mathrm{e}}+\frac{1}{\eta_{t}^{\mathrm{B}}}
$$

where $i^{\mathrm{e}}$ is a polynomial in anticipations of the interbank rate, and $\eta_{t}^{\mathrm{B}}=\left|1 / l_{t} \partial l_{t} / \partial r_{t}\right|$ is the Bertrand semi-elasticity of the demand for new credit at time $t$. That is, the bank will set at time $t$ the loans rate with a margin over its (weighted) expectations on the interbank rate, this margin depending on the inverse of the elasticity of current demand for new credit. In addition, the 
marginal cost definition implied by (1) can easily be enlarged to include management costs $^{4}$ and risk. ${ }^{5}$

If banks play a game other than Bertrand, the profit maximization objective must be changed accordingly and the elasticity obtained in the analogous of (1) will reflect the assumed interactions among rivals.

\section{The industry model: Demands and equilibria}

Now we must specify the individual bank demands for new credit $l_{i}=l_{i}\left(r_{i}, r_{\mathrm{R} i}\right)$, where $i=1 \ldots N$ and we drop the time subindex for simplicity. Next, we must specify the alternative types of behaviour we are going to consider and test. Our specifications are based on the presumption that the global market consists of many independent geographic submarkets. In addition we suppose that banks operate across these submarkets without discriminating rates geographically (which generally seems to be the case in banking), but this is not a crucial assumption and could be relaxed and the model adapted.

\subsection{Demands specification and estimation}

We take global unrestricted demands to be

$$
l_{i}=a_{i}-b_{i} r_{i}+\sum_{j \neq i} d_{i j} r_{j}, \quad i, j=1 \ldots N .
$$

This implies, in principle, a matrix of rate effects $B=\left\{\partial l_{i} / \partial r_{j}\right\}$ with $N^{2}$ different elements, that can only be estimated by imposing strong constraints on them. We assume that there are many local markets, that are independent in the sense of the absence of price spillovers among them, and that every bank operates in an arbitrary number of these submarkets where competitors meet. Assume that, at the local level, competing banks are basically symmetric: the own and cross-rate effects of local demands are equal for all the market participants. Supposing for the moment that local markets can be considered identical (except for the identity of the participants), then a number of strong results follow for global demands.

\footnotetext{
${ }^{4}$ Assume that, at time $t$, the bank forecasts a unit management $\operatorname{cost} c^{\mathrm{e}}$ for the $S$ periods (the change over time of this cost is considered negligible). Then, $\mathrm{E}\left(\pi_{t+s}\right)=\left(r_{t}-i_{t+s}^{\mathrm{e}}-c^{\mathrm{e}}\right) \lambda_{s} l\left(r_{t}, r_{\mathrm{R} t}\right)$ and $r_{t}=i^{\mathrm{e}}+c^{\mathrm{e}}+1 / \eta_{t}$.

${ }^{5}$ Assume that at time $t$ the bank forecasts that a fixed proportion $f^{\text {e }}$ of the credits to be cancelled every year will be lost. Then $\mathrm{E}\left(\pi_{t+s}\right)=\left(r_{t}-i_{t+s}^{\mathrm{e}}\right) \lambda_{s} l\left(r_{t}, r_{\mathrm{R} t}\right)-f^{\mathrm{e}}\left(\lambda_{s}-\lambda_{s+1}\right) l\left(r_{t}, r_{\mathrm{R} t}\right)$, and the equation for the rate will be $r_{t}=i^{\mathrm{e}}+\gamma f^{\mathrm{e}}+1 / \eta_{t}$, where $\gamma=1-\left(1-1 / \sum \delta^{s} \lambda_{s}\right) / \delta$. If $\delta$ is close enough to one, $\gamma \simeq 1 / \sum \lambda_{s}$. And, in a stable environment, $f^{\mathrm{e}} \simeq \sum \lambda_{s} \mathrm{fl}$ where fl represents the observed rate of failures in the stock of credit. Therefore, $r_{t} \simeq i^{\mathrm{e}}+\mathrm{fl}+1 / \eta_{t}$.
} 
Firstly, the global own-rate effect of each bank will be proportional to the number of submarkets in which the bank operates. Secondly, the total cross-rate effect of a rival will be proportional to the number of submarkets in which the rival is encountered. ${ }^{6}$ In addition, the cross-rate effects of any two competitors will be symmetric, because they depend exclusively on the number of coincidences across markets.

However, actual local markets differ from each other in one apparent characteristic: the number of banks. ${ }^{7}$ In this case, the constraints implied by the independent geographic submarkets hypothesis change slightly. The own-rate effects may again be considered proportional to the number of markets in which the bank operates (though now only approximately) and symmetry is preserved, but the correct assessment of cross-effects must weight the coincidences with a rival according to the expected effect of each coincidence given the number of banks in the place of the match. ${ }^{8}$

According to the above discussion suppose there are $K$ local markets, which we index by $k$. Call $b$ the local own-rate effect, which we take as invariant across markets. Call $d$ the coefficient of the market $k$ common cross-rate effect, which we specify varying across markets as $d v\left(N_{k}\right)$ with $v^{\prime}<0$. Then, aggregating across markets, $b_{i}=b K_{i}$, where $K_{i}$ is the number of markets at which bank $i$ operates; and $d_{i j}=d K_{i j}$, where $K_{i j}=\sum_{k, i, j \in k} v\left(N_{k}\right)$ (a weighted sum of coincidences). We can then construct two indices that embody these constraints, $r_{i}^{*}=\left(K_{i} / K\right) r_{i}$ and $r_{\mathrm{R} i}^{*}=\sum_{j \neq i}\left(K_{i j} / K\right) r_{j}$. Using these indices (2) can be transformed in an equation with only two price parameters to be estimated, $l_{i}=a_{i}+b_{1} r_{i}^{*}+b_{2} r_{\mathrm{R} i}^{*}$ with $b_{1}=b K$ and $b_{2}=d K$. However, the whole matrix $B$ of rate effects can be recovered from this estimation given the $K, K_{i}$ and $K_{i j}$ numbers.

\subsection{Equilibria and testing}

Let us turn now to the supply side of the market. We envisage banks as having previously carried out their location decisions across markets and then

\footnotetext{
${ }^{6}$ Note that this effect is bounded by the size of the incumbent and, more importantly, it does not follow automatically from the size of the rival.

${ }^{7}$ This number must be considered endogeneous in the long run, jointly determined by the size of the local market (the number and income of consumers), the fixed cost associated with entry, and the industry degree of toughness in price competition.

${ }^{8}$ In a market with a given degree of product differentiation and linear demands, the demand intercept for each firm decreases with $N$, while the (absolute value of the) own-price effect and the sum of the cross effects increase. The elasticities of the own-price effect and the sum of the cross-effects with respect to $N$ are, however, of order $1 / N$, and hence the changes from market to market can be perhaps neglected. But the elasticities of the intercept and the individual cross-effects with respect to $N$ will usually not be far from unity and must be taken into account. On all this see Jaumandreu and Lorences (1997).
} 
competing in rates given these decisions. Therefore, in setting rates, each bank takes its global demand as given and conveying the relevant information about the effects of its own and rivals' rates on demand.

Now we must specify the set of equilibrium outcomes resulting from the competing behavioural hypotheses. Firstly, it seems natural to take the behaviourally symmetric equilibria of Bertrand-Nash and full collusion as extreme competitive benchmarks. The Cournot-Nash equilibrium also appears as a useful intermediate case (on Bertrand and Cournot in a differentiated product context see Vives (1985)). But symmetric behaviour seems, a priori, not very realistic in a structurally strong asymmetric market. Large competitors are likely to act strategically with respect to their major rivals found in many submarkets. Smaller competitors are likely to present tougher competition to big rivals in the places they coincide. In addition, alliances among more or less complementary banks may arise as a way of increasing market coverage. We must include therefore the possibility that groups of banks coordinate (explicitly or implicitly) their pricing, in the sense of taking into account the cross effects of their rates, playing more or less competitively with respect to the rest of the banks (i.e. the price coalitions studied by Deneckere and Davidson (1985)). We will do that by adding a version of the two competitive equilibria already mentioned with coordination of the banks belonging to the same corporate group (Bertrand-Nash by groups and Cournot-Nash by groups), and also a partial collusion or price coalition equilibrium, in which a broader, but definite group of banks, coordinates and plays Bertrand with respect to the rest.

Assume that there are $G$ non-overlapping groups, indexed $g=1 \ldots G$. Specify behaviour by maximizing the joint profits by groups (or total profits for full collusion), selecting the suitable variable (prices or quantities). The first order conditions corresponding to each of the six equilibria mentioned above may be obtained from the equations that follow, derived by solving the relevant dynamic problems as set out in Section 2 and simplifying the solutions by writing them in terms of $i$ :

$$
\begin{aligned}
& l_{i}+\left(r_{i}-i^{\mathrm{e}}\right) \frac{\partial l_{i}}{\partial r_{i}}+\sum_{\substack{j \neq i \\
i, j \in g}}\left(r_{j}-i^{\mathrm{e}}\right) \frac{\partial l_{j}}{\partial r_{i}}=0, \quad i=1 \ldots N, g=1 \ldots G, \\
& \left(r_{i}-i^{\mathrm{e}}\right)+l_{i} \frac{\partial r_{i}}{\partial l_{i}}+\sum_{\substack{j \neq i \\
i, j \in g}} l_{j} \frac{\partial r_{j}}{\partial l_{i}}=0, \quad i=1 \ldots N, g=1 \ldots G .
\end{aligned}
$$

Eq. (3) represents Bertrand by groups, but collapses to Bertrand if every group consists of a single firm, and gives the formulae corresponding to a price coalition if we assume there is only one global group of colluding firms, say the group $h$. Eq. ( $\left.3^{\prime}\right)$ corresponds to Cournot equilibria and can also represent full collusion when all firms are taken to belong to a unique group. 
By solving the appropriate systems, we can obtain the series of price equations analogous to (1), $r_{i}=i^{\mathrm{e}}+1 / \eta_{i}^{E}$ for $i=1 \ldots N$, where we express margins over costs in terms of semi-elasticities, and where $E$ indexes the equilibrium concepts (see Appendix A). Given (2), obtaining explicit individual expressions for the semi-elasticities involved in all the non-Bertrand equilibria is precluded. The reason is that these expressions include elements of the inverses of either the whole rate effects matrix or specific submatrices of it. This suggests a twostep procedure for testing for the equilibrium outcomes. First, obtain an estimate of the whole rate effects matrix. Then, compute the semi-elasticities corresponding to the different equilibrium concepts, and test for their relative merits in explaining the price-cost data.

The equilibrium that best fits the data can be determined as follows. Given the semi-elasticities, we can estimate the corresponding set of price equations of the type $r_{i}=i^{\mathrm{e}}+\beta\left(1 / \hat{\eta}^{E}\right)+u_{i}$, where $u_{i}$ is a disturbance term and $\beta$ is an auxiliary parameter whose value can be taken as a specification test. These price equations are overlapping models that can be compared by means of a Vuong-type test for model selection (see Vuong, 1989).

\section{The Spanish loans market and the data}

Our sample period, 1983-1991, is a time of important regulatory and structural changes for the whole of Spanish banking activity (see Table 1). ${ }^{9}$ On the regulatory side, the period is a time of increasing liberalization, particularly with respect to banking rates and entry. On the structural side, a mix of trends must be noted. Firstly, banks find an increasingly serious rival in savings banks, which extend their activities, thereby becoming closer competitors. On the contrary, direct entry was only constituted by the opening of central offices of foreign banks, and its immediate competitive effect is probably very small, despite its apparent quantitative importance. Secondly, there is an increase in concentration. At the beginning of the period, several small banks went bankrupt; at the end of the period, there was a wave of mergers and acquisitions.

To simplify things, we have dealt with turbulence (small entry and exit), and also with mergers and acquisitions, in the simplest form: we have dropped banks that were born or died in these years from the sample, and we have treated the merging parts as a single entity during the whole period. ${ }^{10}$ Thus, we work with a balanced panel. This gives the 79 entities sample that we use in the tables and the econometric work. This sample accounts for more than $90 \%$ of private bank loans.

\footnotetext{
${ }^{9}$ Details on this process, in an analysis at the European level, may be found in Gual and Neven (1992). On competition banks vs. savings banks, see Coello (1996).

${ }^{10}$ Unfortunately, the time dimension of the panel renders very difficult any other treatment of mergers.
} 


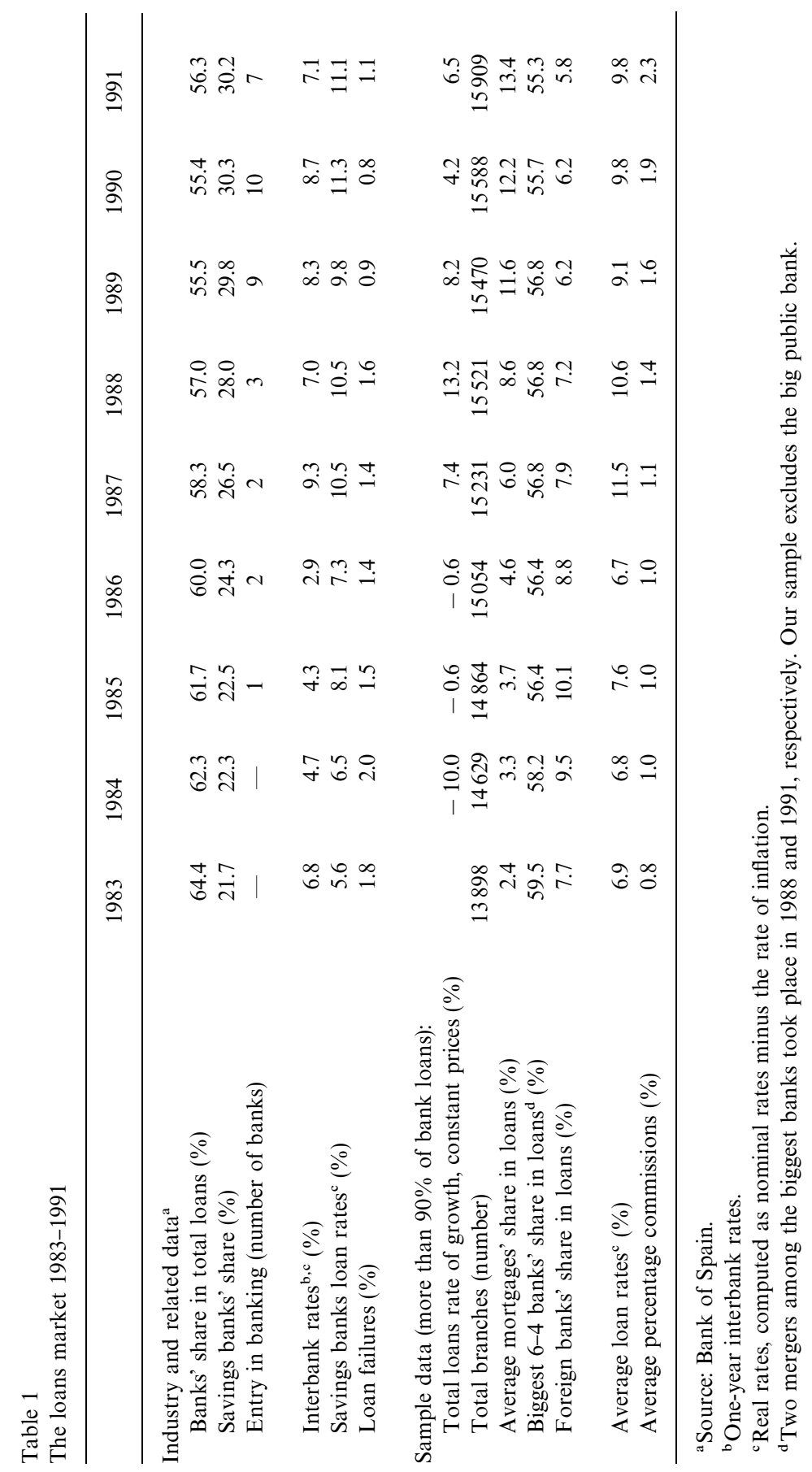


Our basic data consists of individual yearly observations on the total amount of credit granted, and the declared preferential (best client) rates charged, as well as detailed information on the geographical areas in which they operate (the number of branches they hold in each of the 51 administrative divisions or provinces, on a yearly basis). In addition, for every bank we know the total amount charged by way of percentage commissions, we have some information on the structure of the loans, and we know the total amount of management costs and the value of deposits. All this information comes from the individual yearly balance sheets published by the banks' trade association (AEB), with the exception of the rates. The preferential rates are individually declared on a monthly basis to the Bank of Spain. The rates we use are the yearly averages of the rates declared for 1-year loans. To avoid the effects of the regulatory changes, we will use what we call the effective rates on loans, or loan rates plus the percentage commissions on loans.

Table 2 summarizes the structure of the industry. Size asymmetry and concentration are very strong, and are clearly associated with the geographical coverage of the national territory with the networks of branches. Half of the banks are involved in corporate groups (identified by the trade association). These groups are led by the banks with national scope, and the degree of financial and decisional control of the small group members is usually high.

The average of the (preferential) loan rates set by the banks shows a clear relationship with the interbank rate, disrupted only by two yearly interbank rates that are especially high due to monetary regulations (see Table 1). It is known that a change in short-run banking behaviour took place in 1989, in the form of a price war over the compensation on deposits. It is frequently analysed as a reaction of the banks to the increasing competition from savings banks. From Table 1 it is clear that this change did not affect, at least at this moment, behaviour in the loans market.

\section{Empirical specification}

Firstly, we must specify the empirical relationship aimed at estimating the new credit demands' parameters. Unfortunately, we can only directly observe the banks' stock of total credit $L$ at each moment $t$. However, we know that $L_{t}=l_{t}-c_{t}+L_{t-1}$, where $c_{t}$ represents cancellations of credits at $t$. If the structure of the $\lambda$ 's is close to an exponential law $\left(\lambda_{s} \simeq \lambda^{s}\right)$, it is easy to show that this identity can be approximated by the relationship $L_{t}=l_{t}+\lambda L_{t-1}$, where $l_{t}$ and its parameters may be estimated at the same time as $\lambda$.

Accordingly, we specify the demand equation as

$$
L_{i t}=a_{i}+a^{\prime} z_{i t}+b_{1} r_{i t}^{*}+b_{2} r_{\text {Rit }}^{*}+b_{C} r_{C i t}^{*}+\left(\lambda_{0}+\lambda_{1}^{\prime} x_{i t}\right) L_{i t-1}+u_{i t},
$$




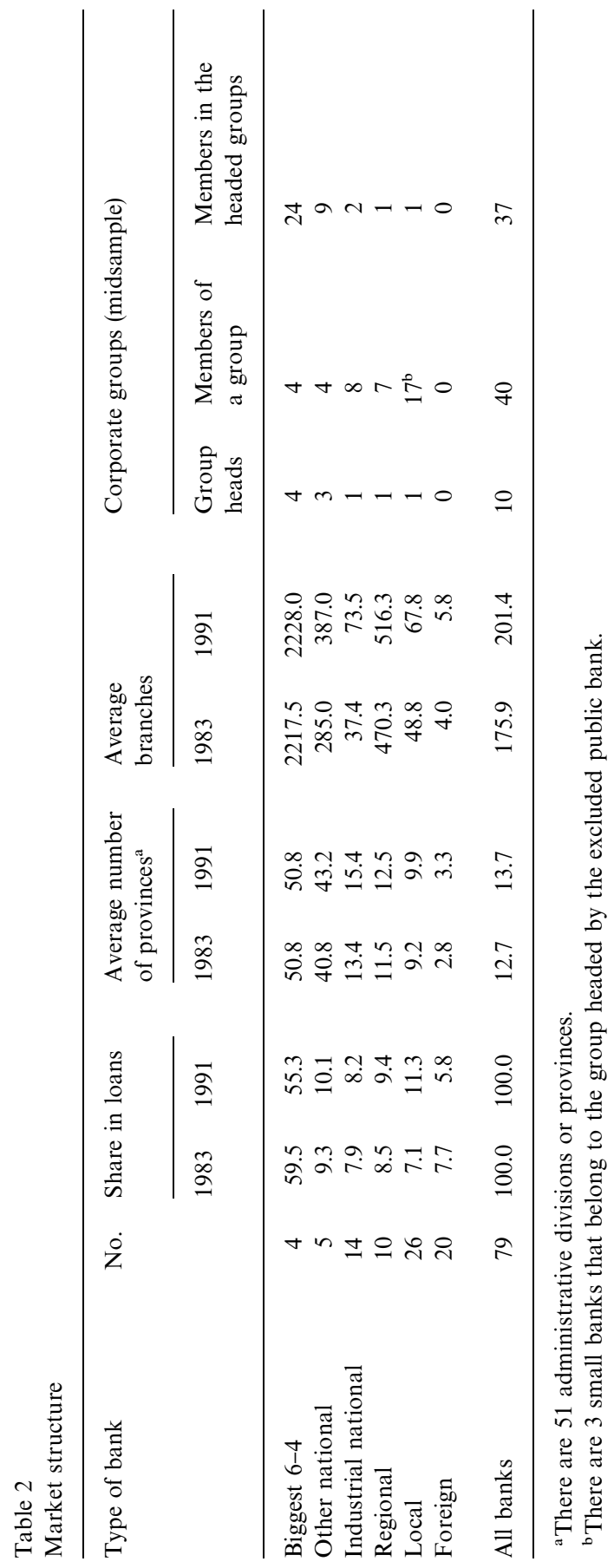


where $L$ is total real loans, in thousands of millions of (1983) monetary units, and the $r^{*}$ 's are the (indices of) real effective interest rates, expressed in percentage points. We can distinguish three parts. The two first terms, $a_{i}+a^{\prime} z_{i t}$, are destined to model the new credit demand intercepts in two components: an unobservable, bank-specific and time-invariant component, and another depending on a vector of variables $z_{i t}$ to control for specific changes over time. The three following terms are aimed at picking up the effects of the interest rates: own, rivals' and of the savings banks, indexed $C$. Finally, we allow for a variable $\lambda$ parameter, depending on an $x_{i t}$ vector of variables that can shift its value. The term $u_{i t}$ stands for a zero mean random disturbance that we will assume to be uncorrelated across banks and time, but cross-sectionally heteroscedastic.

The data on branches of the 79 banks in 51 provinces during 9 years offer more than 35000 figures that we have used to build up the weighting scheme. Provinces are obviously not the small independent markets that we envisage in the theoretical model, but we use these data together with some ancillary assumptions to approximate the weight of the underlying small independent submarkets. The weighted interest rates indices have been calculated as $r_{i t}^{*}=w_{i t} r_{i t}, r_{\mathrm{R} i t}^{*}=\sum_{j \neq i} \sum_{m} w_{i j m t} r_{j t}=\sum_{j \neq i} w_{i j t} r_{j t}$ and $r_{C i t}^{*}=\sum_{m} w_{i m t} C_{m t} r_{C t}$, where $w_{i t}$ is the approximation of the proportion of total markets in which the bank is present $\left(K_{i} / K\right)$, and $w_{i j m t}$ is the approximation of the weights of the markets of province $m$ in which competitors $i$ and $j$ coincide, that takes into account the number of rivals (the sum of $w_{i j m t}$ across provinces approximates $\left.K_{i j} / K\right)$. Finally, $w_{i m t} C_{m t}$ constitutes a province-specific measure of the competitive pressure of savings banks on bank $i$. Appendix B gives details.

The $z_{i t}$ intercept vector includes the proportion $w_{i t}$ to account for the expansion (or contraction) of the markets where the bank was present during the period, a weighted index of the rate of increase (at time $t+1)$ of the corresponding regional gross domestic products, $\sum_{m} w_{i m t} \mathrm{GDP}_{m t+1}$, and the same variable interacting with a dummy foreign bank. The right modelization of the $\lambda$ parameter is an important issue if the intertemporal structure of loans is different from bank to bank, or has been changing over time. These two dimensions of heterogeneity are present, and the lagged proportion of mortgages in the total loans $m t g_{i t-1}$ and a cyclical inverse indicator (the rate of failures in credits $\mathrm{fl}_{t}$ ) are the variables used to account for them.

We specify the interest rate equations as

$$
r_{i t}=\gamma_{i}+\sum_{s=0}^{s} \gamma_{s} i_{t+s}+\gamma \mathrm{fl}_{t}+\gamma^{\prime} \cos t_{i t}+\beta \frac{1}{\hat{\eta}_{i t}^{E}}+v_{i t}
$$

where $\gamma_{i}$ represents potential individual effects invariant over time, the $i$ 's are the anticipations of the interbank deposit rates to be included in the polynomial on expectations (replacing the $i^{\mathrm{e}}$ 's), $\mathrm{fl}_{t}$ (failures) is the variable intended to control for time-varying risk, $\operatorname{cost}_{i t}$ is an indicator of the management costs computed as 
(wages + other expenditures)/(loans + deposits), and $v_{i t}$ stands for a zero mean random disturbance that we will assume to be homoscedastic and uncorrelated across banks and time. In practice, we will limit ourselves to considering polynomials that include only 3 years (the current year and two anticipations) and we will constrain the coefficients to sum unity. Individual effects invariant over time may stem in this equation from some omitted variables (in particular, the risk premiums related to a specialized composition of the loans, or simply their degree of diversification).

To estimate the inverse of the elasticities to be included in (5), we use the formulas developed in Appendix A substituting $\hat{B}$ for $B$. The estimated matrices $\hat{B}_{t}$ are obtained by using $w_{i t} \hat{b}_{1}$ as diagonal elements, and $w_{i j t} \hat{b}_{2}$ in the corresponding entries. The quantities are replaced by the vector of estimates of the demands for new credit at time $t$, whose elements are $\hat{i}_{i t}=\hat{a}_{i}+\hat{a}^{\prime} z_{i t}+\hat{b}_{1} r_{i t}^{*}+$ $\hat{b}_{2} r_{\mathrm{R} i t}^{*}+\hat{b}_{C} r_{C i t}^{*}$, where $a_{i}$ is estimated as $\hat{a}_{i}=1 / T \sum_{t}\left(L_{i t}-\hat{a}^{\prime} z_{i t}-\hat{b}_{1} r_{i t}^{*}-\right.$ $\left.\hat{b}_{2} r_{R i t}^{*}-\hat{b}_{C} r_{C i t}^{*}-\hat{\lambda} L_{i t-1}\right)$. For the concrete equilibria considered, see the next section.

From an econometric point of view, some characteristics of these equations must be noted. Firstly, the two equations form a simultaneous model, hence $L$ and $r^{*}$ are endogenous variables. In addition, the replacement of expected values by observations in the second equation raises another source of correlation with the error term. Secondly, both equations include the presence of individual effects, presumably correlated with part of the included variables. ${ }^{11}$ Thirdly, the sharp size inequality among banks, related to the number of markets in which they operate, leads us to expect a strong cross-sectional heteroscedasticity in the estimation of the demand relationship. ${ }^{12}$ We address these questions in a GMM framework, estimating in first differences and using heteroscedasticity corrections and robust statistics.

\section{Econometric results}

Table 3 reports the best results obtained in estimating the demand equation. The estimation is carried out by treating the $r^{*}$ 's, the loan proportions and the loan failures indicator as endogenous variables, and the lag in total credit as predetermined (see the table for details about the instruments used). The estimated equation performs quite well and all the coefficients present the right signs and a nice interpretation. We only comment selectively and skip the econometric details to save space.

\footnotetext{
${ }^{11}$ Non-exogeneity plus potentially correlated individual effects imply the use of the IV estimators considered by Holtz-Eakin et al. (1988) and Arellano and Bond (1991), among others.

${ }^{12} \mathrm{We}$ use the normalized weights $\left[1 /\left(1+\left(\mathrm{AO}_{i} / k\right)^{2}\right)\right]^{1 / 2}$, where $\mathrm{AO}_{i}$ is the time average of the individual $i$ branches and $k=100$. In any case we use and report White-robust heteroscedasticity estimates.
} 
Table 3

Demand equation. No. of banks: 79; sample period ${ }^{a}$ : 1986-1991; no. of observations: 474; dependent variable: $L_{i t}$.

\begin{tabular}{|c|c|c|c|}
\hline \multirow[t]{2}{*}{ Independent variables } & \multirow[t]{2}{*}{ Parameters } & \multicolumn{2}{|c|}{ Estimation procedure: Differences, GMM } \\
\hline & & One-step estimates ${ }^{\mathrm{c}}$ & Two-step estimates \\
\hline Proportion of markets & $a_{1}$ & $\begin{array}{r}1146.4 \\
(2.0)\end{array}$ & $\begin{array}{r}1155.2 \\
(2.3)\end{array}$ \\
\hline Regional GDP effects & $a_{2}$ & $\begin{array}{l}20.9 \\
(1.4)\end{array}$ & $\begin{array}{l}25.7 \\
(2.1)\end{array}$ \\
\hline GDP effects $\times$ foreign & $a_{3}$ & $\begin{array}{l}-160.7 \\
(-2.0)\end{array}$ & $\begin{array}{c}-139.2 \\
(-2.3)\end{array}$ \\
\hline$r_{i t}^{*}$ & $b_{1}$ & $\begin{array}{l}-283.4 \\
(-2.4)\end{array}$ & $\begin{array}{l}-296.2 \\
(-2.9)\end{array}$ \\
\hline$r_{\text {Rit }}^{*}$ & $b_{2}$ & $\begin{array}{c}11.2 \\
(1.8)\end{array}$ & $\begin{array}{l}12.6 \\
(2.3)\end{array}$ \\
\hline$r_{c i t}^{*}$ & $b_{3}$ & $\begin{array}{r}253.2 \\
(2.4)\end{array}$ & $\begin{array}{r}224.5 \\
(2.5)\end{array}$ \\
\hline$L_{i t-1}$ & $\lambda_{0}$ & $\begin{array}{c}0.56 \\
(2.38)\end{array}$ & $\begin{array}{c}0.61 \\
(3.47)\end{array}$ \\
\hline$m t g_{i t-1} \times L_{i t-1}$ & $\lambda_{11}$ & $\begin{array}{c}1.7 \\
(1.4)\end{array}$ & $\begin{array}{l}2.4 \\
(2.2)\end{array}$ \\
\hline$m t g_{i t-1}^{2} \times L_{i t-1}$ & $\lambda_{12}$ & $\begin{array}{l}-13.5 \\
(-2.0)\end{array}$ & $\begin{array}{l}-16.5 \\
(-3.3)\end{array}$ \\
\hline $\mathrm{fl}_{t} \times L_{i t-1}$ & $\lambda_{13}$ & $\begin{array}{c}0.13 \\
(1.68)\end{array}$ & $\begin{array}{c}0.15 \\
(2.92)\end{array}$ \\
\hline Instruments $^{\mathrm{d}}$ & $\begin{array}{l}\text { Lag } t-2 \text { of } \\
m t^{i t-2}, m t g \\
\text { branches }_{i t}, i_{t}\end{array}$ & $\begin{array}{l}\text { commercial loans } \\
\text { it }\end{array}$ & \\
\hline \multicolumn{4}{|l|}{ Statistics ${ }^{\mathrm{b}}$} \\
\hline$m_{1}$ & & -2.09 & -2.45 \\
\hline$m_{2}$ & & 0.45 & 0.58 \\
\hline Sargan test & & 5.43 & 1.67 \\
\hline$(\text { degrees of freedom })^{\mathrm{e}}$ & & (5) & $(5)$ \\
\hline
\end{tabular}

${ }^{\text {a }}$ The estimation sample is determined by the use as an instrument of the differences of the dependent variable lagged twice.

${ }^{\mathrm{b}}$ For the GMM method in this context and the $m$ statistics see Arellano and Bond (1991).

${ }^{\mathrm{c}}$ Robust $t$-ratios in parentheses.

${ }^{\mathrm{d}}$ Only the three first explanatory variables are considered exogenous.

${ }^{\mathrm{e}}$ Total instruments minus included variables.

On the whole, the average estimated $\lambda$ has a value of 0.81 , with a crosssectional average standard deviation of 0.10 , which increases over time (in the last 2 years it reaches the values 0.13 and 0.17 ). Recall the rate's coefficients 
interpretation: the own-rate coefficient represents the effect that a bank present in all the local submarkets would have on its own demand, and the cross-rate coefficient is the effect of the rate set by a competitor encountered in every one of these markets. Both coefficients have the right sign, they are estimated with remarkable precision, and the ratio of their values agrees with what is expected from theory. Similarly, the rate set by the savings banks shows an important effect of the right sign although somewhat upward-biased (for example, it exceeds the average effect expected from rival banks; we attribute this to the use of an aggregate rate whose effects are hard to disentange from other macroeconomic factors).

When the own and cross coefficients are used to estimate the whole $B$ matrix, and this matrix together with the estimated demands are employed to compute the inverse of the semi-elasticities $1 / \eta_{i}^{E}$ (or implied mark-ups), the results are reasonable. For example, the average value of the Bertrand mark-ups is estimated at 2.6 percentage points, which corresponds to an absolute value of the elasticity of demand with respect to the real interest rate of 4.2.

Table 4 presents some estimates of the rates equation. We have systematically estimated the alternative overlapped models that include, per turn, the computed $1 / \eta_{i}^{E}$ of the following equilibria: Bertrand, Cournot, collusion, Bertrand by groups, Cournot by groups, collusion of the four biggest banks (and their corporate groups), and collusion among all the national banks (and their groups). We only report the results of the extreme cases of Bertrand and full collusion and the models of partial collusion.

Estimation is carried out assuming that none of the included variables are exogenous, and the set of instruments remain invariable. To ensure that inferences are robust to the use of previously estimated variables, we have computed, for every equilibrium, two equation estimates and three sets of standard errors. ${ }^{13}$ One-step estimates use a GMM weighting matrix - common to all the equilibria - based on the instruments and the conventional disturbances structure to be expected from a panel-differenced model. Along one-step estimates we report $t$-ratios corresponding to two types of standard errors: robust standard errors, based on a consistent estimate of the asymptotic variance of the moments that uses the estimated residuals, and corrected standard errors, based on the additional consideration in the computation of this variance that one variable is a previously estimated variable. Corrected standard errors indicate a considerably lower degree of precision in the estimates of the coefficients associated to the previously computed variables. Two-step estimates then use the inverse of

\footnotetext{
${ }^{13}$ Sequential estimation procedures make it convenient to compute covariance matrices that take into account the use of previously estimated variables in order to avoid misleading inferences (see, for example, Newey, 1984; Pagan, 1986). We develop and apply a covariance estimation procedure that takes into account that the price effects that make up $\hat{B}$ have been previously estimated (we owe the approach to Arellano). An appendix with the formulae is available upon request.
} 


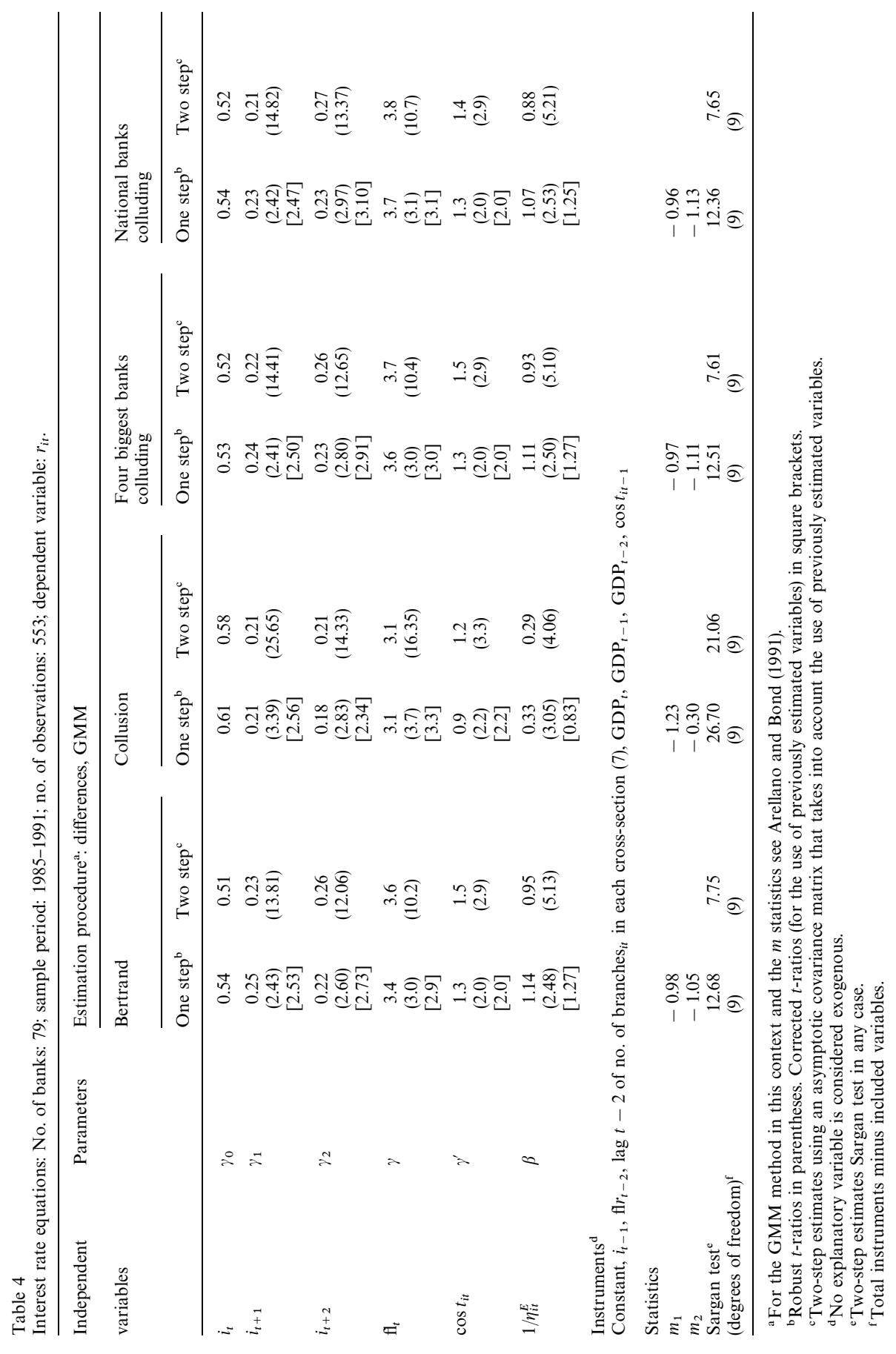


the more complete consistent estimation of the asymptotic variance of the moments as a weighting matrix, to obtain the optimal or efficient GMM estimator, which gives low standard errors and high $t$-ratios. Changes in the coefficients are clearly small.

Several aspects of the estimations deserve comment. Firstly, all the estimates strongly support the interbank anticipations specification of the marginal cost: the two anticipations included are always very significant, and the polynomial has a sensible pattern. Secondly, the varying risk seems to be an important component of the rates set by banks. Thirdly, the approximation of the management unit costs performs quite well in every model, and its coefficient is not far from unity. Finally, and most important for our purposes, in all the models (with the exception of the full collusion case) the computed variables attract coefficients not far from unity. This validates the general size and meaning of the variables computed from the demand estimates.

To select among models, we apply a Vuong-type test (see Vuong, 1989). The Vuong test is a likelihood-ratio test to select among non-nested or overlapping models. Given our method of estimation, we have adapted the test, computing it with the GMM analogous to the likelihood ratio, $N$ times the difference between the minimized value of the objective function (Ogaki, 1993). That is, for every two models, we compute the values

$$
\mathrm{VT}=\frac{N\left(J_{2}-J_{1}\right)}{\left[\sum\left(J_{i 1}-J_{i 2}\right)^{2}-N\left(J_{1}-J_{2}\right)^{2}\right]^{1 / 2}},
$$

where $J_{1}$ and $J_{2}$ are the respective minimized values of the objective function, $J_{i 1}$ and $J_{i 2}$ are the individual values of the objective function evaluated at the minimum, and $N$ the number of observations. We expect this statistic to be distributed as a $N(0,1)$ (for the working of the test see Table 5). Alternatively, notice that the numerator of the test coincides with the difference between the Sargan tests of overidentifying restrictions, usually employed in testing the validity of moment restrictions. We apply the test with the one-step estimates, which are all obtained with the same weighting matrix, in order to reduce the sample variability effect associated with the estimation of this matrix.

Table 5 reports the results of systematically comparing every pair of models. The table shows that the simple Bertrand and Cournot equilibria are clearly rejected against all the alternatives that embody some coordination of groups of firms, and only tend to be accepted as better models than full collusion. On the other hand, Bertrand is accepted as better that Cournot, but is indistinguishable from Cournot by groups. The rest of the tests are slightly more imprecise, but the only model that always performs better than the alternatives is the model corresponding to a price coordination of the national banks (see the last column 
Table 5

Test of the price equilibrium hypotheses ${ }^{\mathrm{a}, \mathrm{b}}$

\begin{tabular}{|c|c|c|c|c|c|c|}
\hline & Cournot & Collusion & $\begin{array}{l}\text { Bertrand by } \\
\text { groups }\end{array}$ & $\begin{array}{l}\text { Cournot by } \\
\text { groups }\end{array}$ & $\begin{array}{l}\text { Four biggest } \\
\text { banks } \\
\text { colluding }\end{array}$ & $\begin{array}{l}\text { National } \\
\text { banks } \\
\text { colluding }\end{array}$ \\
\hline Bertrand $^{\mathrm{c}, \mathrm{d}}$ & 3.41 & 1.68 & -2.51 & -0.10 & -2.26 & -2.02 \\
\hline Cournot & & 1.56 & -5.09 & -28.47 & -3.36 & -2.76 \\
\hline Collusion & & & -1.73 & -1.66 & -1.84 & -2.06 \\
\hline Bertrand by groups & & & & 1.15 & -1.26 & -1.58 \\
\hline Cournot by groups & & & & & -1.46 & -1.73 \\
\hline $\begin{array}{l}\text { Four biggest banks } \\
\text { colluding }\end{array}$ & & & & & & -1.58 \\
\hline
\end{tabular}

${ }^{\text {a }}$ Vuong-type test, computed with the GMM analogous to the likelihood ratio.

${ }^{\mathrm{b}}$ Test values based on the one-step estimates.

${ }^{\mathrm{c}} \mathrm{A}$ row value above (below) the critical value (minus the critical value) means that the row model can be accepted as better (worse) than the column model.

${ }^{\mathrm{d}}$ Critical value at the $20 \%(10 \%, 5 \%)$ level of significance in a one-sided test is $1.28(1.64,1.96)$.

of the table). Given these results, the collusion of all national banks can be claimed as the model that best fits the data. ${ }^{14}$

\section{Welfare analysis}

Let us now consider welfare analysis starting from our estimates. Fig. 1 depicts two possible loans market equilibria for a bank (Bertrand and a collusive one). Independent (Bertrand) maximization implies setting a rate on loans $r$ (corresponding to the equality of marginal revenue and marginal cost $c=i^{\mathrm{e}}+$ other components, given the rivals' rates), but collusion implies setting a higher rate on a higher new credit demand curve (shifted because of the rivals' simultaneous higher rates). The figure illustrates the dead-weight loss attributable to the Bertrand and collusive equilibria.

The welfare loss induced by market power in current new credit demand can be computed by adequate integration of the areas under the demand curves comprised between marginal costs and the rates charged by banks, and then subtracting the profits derived from market power. With linear demands, it is

${ }^{14}$ Two-step estimates give similar test results, but rather more inconclusive. Price coordination of the four biggest banks tends to be accepted as better than the rest of the models, but is indistinguishable from coordination of all national banks. 


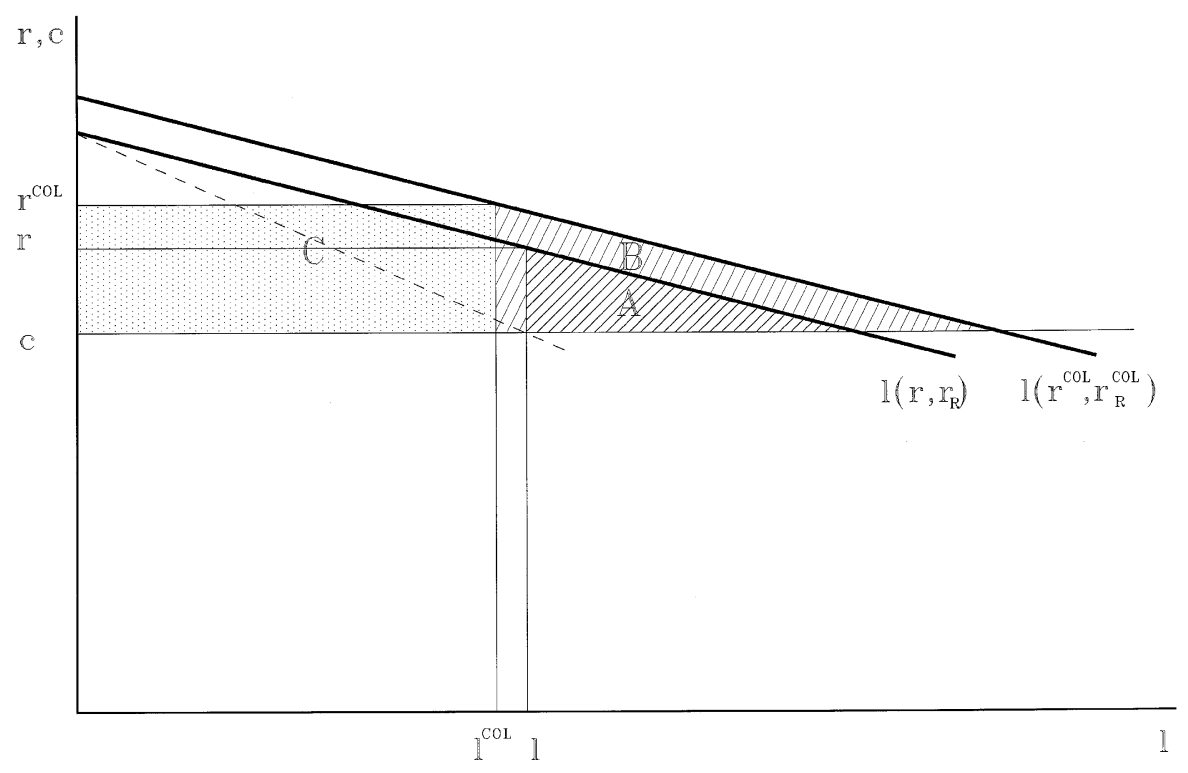

Fig. 1. Dead-weight loss and monopoly profits for a bank in the loans market. $1(\cdot)$ : demand for loans; $\mathrm{c}: i^{\mathrm{e}}+$ other marginal cost components; $r, r^{\mathrm{COL}}$ : Bertrand and collusion rates; A: Bertrand dead-weight loss; A + B: collusive dead-weight loss; C: collusive profits.

easy to show that all we need to carry out these computations are the individual mark-ups and the own and cross-price effects. ${ }^{15}$ That is,

$$
\begin{aligned}
D & =\sum_{i} \int_{c_{i}}^{r_{i}} l_{i}\left(r_{1} \ldots r_{i-1}, z_{i}, c_{i+1} \ldots c_{N}\right) \mathrm{d} z_{i}-\sum_{i}\left(r_{i}-c_{i}\right) l_{i}(r) \\
& =\sum_{i}\left(r_{i}-c_{i}\right)\left[\frac{b_{i}}{2}\left(r_{i}-c_{i}\right)-\sum_{j>i} d_{i j}\left(r_{j}-c_{j}\right)\right] .
\end{aligned}
$$

The selection of an equilibrium provides us with an estimate of the individual price-cost mark-ups. In addition, as we also have an estimate of the most competitive Bertrand mark-ups, we are able to split approximately our welfare measure into two different components: the proportion derived from the predetermined level of product differentiation, and the part attributable to the price coordination of the firms (see Fig. 1). To obtain intuitive measures, we scale them according to the size of the market, in this case the total amount of interests paid during the year for the new credit.

${ }^{15}$ See Spence (1976). 
On the other hand, assume that computations give a dead-weight loss $D_{t}$ at time $t$. But, at this time, there are also remaining consumers paying the rates set by banks for the credits opened the $S$ previous years $\left(L_{t}=\sum_{s=0}^{S} \lambda_{s} L_{t-s}\right)$. If demand for new credit is more or less stationary and the dead-weight loss has not changed too much over time, an additional rough estimate for the total or accumulated current dead-weight loss is $D=(1 /(1-\lambda)) D_{t}$.

The numbers implied by these exercises demonstrate that the consequences of market power in the loans market are far from negligible. If we take the colluding national banks as the market equilibrium, the average 1985-1991 relative dead-weight loss is evaluated at 8.2 percentage points, and 10 for the last 2 years. Up to one-fourth of this loss in some years was due to price coordination. The relative average monopoly profits are evaluated in $19.1 \%$ of the market, and one-tenth of these profits arise from collusion. Keep in mind that these are figures for new credits each year. Taking these figures as valid for the whole market during the period studied, they imply that the accumulated dead-weight loss in the loans market could have reached about one percentage point of the national GDP those years.

\section{Conclusion}

We have presented a simple way to estimate constrained individual demand price effects (using panel data), in a market with product differentiation where many firms compete in many submarkets. Then we have estimated a price equation to assess the likelihood of different equilibrium outcomes, using the previous estimates to specify the corresponding firms' mark-ups. This equation is at the same time aimed at estimating the firms' relevant marginal cost (or marginal costs). Finally, the estimated demand parameters, together with the equilibrium mark-ups, have provided an easy way to conduct welfare analysis.

The application of these methods to the assessment of competition in the Spanish loans market from 1983 to 1991 has provided enlightening results in a context which is not easy to analyse. The demand parameters have been sensibly estimated and show a highly elastic demand for new credit. The target of the banks also seems rightly modelled as aimed at establishing a margin over their expectations on the interbank rates. The test to discriminate among equilibria suggests that the type of strategic interaction that best fits the data is the national (and biggest) banks' internalizing each others' cross price effects, the rest of the banks playing Bertrand. That is, we detect a price coalition practicing price coordination during the period, with the result being a strong dead-weight loss.

\section{Acknowledgements}

Luis Orea and Rebeca de Juan provided efficient research assistance at different stages of this work. We are grateful to Manuel Arellano, Miguel 
Delgado, Consuelo Pazó, Robert Porter, Xavier Vives and to three anonymous referees for several suggestions. We have also received useful comments on this work from O. Bover, J.M. Campa, J.C. Fariñas, J. Gual, X. Martínez-Giralt, A. Martín Marcos, R. Repullo, V. Salas and J. Segura. A previous version of this paper was presented at the 23rd EARIE Conference.

\section{Appendix A. Obtaining the semielasticities}

The matrix resolution of $(3)$ and $\left(3^{\prime}\right)$, gives

$$
\frac{1}{\eta^{B}}=-(\operatorname{diag} B)^{-1} l, \frac{1}{\eta^{C}}=-\left(\operatorname{diag} B^{-1}\right) l \text { and } \frac{1}{\eta^{\mathrm{COL}}}=-B^{-1} l .
$$

Now define $C_{g}$ as an $N \times N$ selection (diagonal) matrix with ones in the diagonal if the $i$ th element corresponds to a firm belonging to the $g$ group and zero otherwise, and $C_{h}$ as the selection matrix corresponding to a unique coalition $h$. Then

$$
\frac{1}{\eta^{B G}}=-\left(\sum C_{g} B C_{g}\right)^{-1} l, \quad \frac{1}{\eta^{C G}}=-\left(\sum C_{g} B^{-1} C_{g}\right) l
$$

and

$$
\frac{1}{\eta^{P C}}=-\left[C_{h} B C_{h}+\left(I-C_{h}\right) \operatorname{diag} B\right]^{-1} l .
$$

\section{Appendix B. Weighting scheme}

For simplicity, we drop the time subindex. Let $O_{i m}$ be the branches of bank $i$ in province $m$. We will assume that the number of local submarkets in province $m$ equals the number of branches of the bank with the highest number, $\max \left\{O_{1 m}, \ldots, O_{N m}\right\}$, and we compute the per-market average number of competitors in province $m$ as $\sum_{i} O_{i m} / \max \left\{O_{1 m}, \ldots, O_{N m}\right\}$. To account for the variability in the number of competitors across markets, we will compute the ratios comp $_{m}$, normalizing the average numbers of competitors by the global average $1 / 51 \sum_{m}\left(\sum_{i} O_{i m} / \max \left\{O_{1 m}, \ldots, O_{N m}\right\}\right)$ computed at the sample time midpoint 1987. Total submarkets, estimated for the same moment, will simply be $\sum_{m} \max \left\{O_{1 m}, \ldots, O_{N m}\right\}$.

According to these calculations, we approximate $K_{i} / K$ by $w_{i}=\sum_{m} O_{i m} / \sum_{m} \max \left\{O_{i m}, \ldots, O_{N m}\right\}$. Coincidences are a bit more problematic. We have to assume that the presences are completely overlapped, and define the market coincidences between $i$ and $j$ in province $m$ as $\min \left\{O_{i m}, O_{j m}\right\}$. 
Our approximation to $K_{i j} / K$ will then be $w_{i j}=\sum_{m}\left(\min \left\{O_{i m}, O_{j m}\right\} \operatorname{comp}_{m}^{-1}\right) /$ $\sum_{m} \max \left\{O_{1 m}, \ldots, O_{N m}\right\}$.

To account for the variability of the savings banks' competitive pressure by provinces, we have computed the ratios $C_{m}$, defined as the quotients $O_{C m} / \sum_{i} O_{i m}$ normalized by the global ratio of branches in 1987 .

The raw data on branches are an imperfect indicator of the presence of banks by submarkets. Firstly, branches cover all banking services and the importance of lending may differ according to specialization (this is especially important for industrial and foreign banks). Secondly, the smallest banks tend to have a few larger branches which are not fully comparable. Therefore, we ultimately used numbers of 'adjusted branches' in our computations (the numbers of real branches multiplied by a ratio representing the variability in employment numbers attributable to the lending activity).

\section{References}

Arellano, M., Bond, S., 1991. Some tests of specification for panel data: Monte Carlo evidence and an application to employment equations. Review of Economic Studies 58, 277-297.

Barros, P., 1999. Multimarket competition in banking, with an example from the Portuguese market. International Journal of Industrial Organization 3, 335-352.

Berry, S., 1994. Estimating discrete-choice models of product differentiation. Rand Journal of Economics 2, 242-262.

Berry, S.T., Levinsohn, J., Pakes, A., 1995. Automobile prices in market equilibrium. Econometrica 2, 889-917.

Bresnahan, T., 1989. Empirical studies of industries with market power. In: Schmalensee, R., Willig, R. (Eds.), Handbook of Industrial Organization, Vol. 2.. North-Holland, Amsterdam.

Coello, J., 1996. El mercado de depósitos español (1985-1994): Bancos versus Cajas de Ahorro. Unpublished Thesis, University of Alcalá de Henares.

De Juan, R., 1999. The independent submarkets model: An application to the Spanish retail banking market, DT 9809, PIE-FEP.

Deneckere, R., Davidson, C., 1985. Incentives to form coalitions with Bertrand competition. Rand Journal of Economics 4, 473-486.

Freixas, X., Rochet, J., 1997. Microeconomics of Banking. MIT Press, Cambridge, MA.

Gasmi, F., Laffont, J.J., Vuong, Q.H., 1992. Econometric analysis of collusive behaviour in a softdrink market. Journal of Economics and Management Strategy 2, 277-311.

Gual, J., Neven, D., 1992. Deregulation in the European banking industry 1980-1991. European Economy 3, 151-183.

Holtz-Eakin, D., Newey, W., Rosen, H., 1988. Estimating vector autoregressions with panel data. Econometrica 56, 1371-1395.

Jaumandreu, J., Lorences, J., 1997. Modelling price competition under product differentiation and many firms (An application to the Spanish loans market), DT 9701, PIE-FEP.

Neven, D., Röller, L., 1999. An aggregate structural model of competition in the European banking industry. International Journal of Industrial Organization 7, 1059-1074.

Newey, W.K., 1984. A method of moments interpretation of sequential estimators. Economics Letters 14, 201-206.

Ogaki, M., 1993. Generalized Method of Moments: Econometric applications. In: Maddala, G.S., Rao, C.R., Vinod, H.D. (Eds.), Handbook of Statistics, Vol. 11. Elsevier, Amsterdam. 
Pagan, A., 1986. Two stage and related estimators and their applications. Review of Economic Studies 53, 517-538.

Pazó, C., Jaumandreu, J., 1999. An empirical oligopoly model of a regulated market. International Journal of Industrial Organization 1, 25-57.

Slade, M., 1986. Conjectures, firm characteristics, and market structure: An empirical assessment. International Journal of Industrial Organization 4, 347-370.

Slade, M., 1992. Vancouver's gasoline-price wars: An empirical exercise in uncovering supergame strategies. Review of Economic Studies 59, 257-276.

Spence, M., 1976. Product differentiation and welfare. American Economic Review 2, 407-414.

Sutton, J., 1998. Technology and Market Structure. Theory and History. MIT Press, Cambridge, MA.

Vives, X., 1985. On the efficiency of Bertrand and Cournot equilibria with product differentiation. Journal of Economic Theory 1, 166-175.

Vuong, Q., 1989. Likelihood ratio tests for model selection and non-nested hypotheses. Econometrica 2, 307-333. 